International Journal of Dentistry and Oral Science (1JDOS)

ISSN: 2377-8075

\title{
Interleukin-22 (IL-22) Gingival Gene Expression and GCF Concentration in Periodontal Health and Disease
}

Amini Behbahani $\mathrm{A}^{1}$, Sattari $\mathrm{M}^{2 *}$, Mofid $\mathrm{R}^{3}$, Ganji $\mathrm{A}^{4}$

$$
\text { Case Report }
$$

${ }^{1}$ Assistant professor, Iran center for dental research, dental school, Shahid Beheshti university of medical sciences, dept. periodontics , dental school, Shiraz university of medical sciences, Iran.

${ }^{2}$ Professor, Iran center for Dental Research, Shahid Beheshti University of medical sciences,Iran.

${ }^{3}$ Professor, dept. periodontics, dental school, Shahid Beheshti university of medical sciences, Iran.

${ }^{4} \mathrm{PhD}$ student, dept. immunology, medical school, Mashhad university of medical sciences, Iran.

\begin{abstract}
IL-22 is a cytokine that is assumed to improve anti-microbial defense of epidermal and epithelial cells and the cells of gastrointestinal and respiratory systems. With respect to absence of enough relevant articles in this regard the aim of this study was to evaluate the correlation between IL-22 gene expression in gingival tissues as well as its concentration in GCF and periodontal diseases. Gingival samples obtained from 60 patients of three different groups (healthy, gingivitis and chronic periodontitis) and used for evaluation. Expression of IL-22 mRNA was measured by Real-time PCR and its concentration in GCF was determined by ELISA. In none of the tissue samples, mRNA of IL-22 was detected; However IL-22 concentration was significantly higher in periodontitis in comparison to other groups and in gingivitis was higher than the normal gingiva. There was no relationship between concentration of IL-22 in GCF and the extent and severity of chronic periodontitis. With respect to the results of this study, probable systemic production of IL-22 in response to periodontopathic bacteria is suspected and it is assumed to counteract with LPS of these bacteria and protect periodontal tissues against adverse effects that results from stimulation of different cells and molecules of immune system by LPS.
\end{abstract}

Keywords: IL-22; Periodontitis; Gingivitis; GCF; Gene Expression.

\section{*Corresponding Author:}

Mandana Sattari DDS, PhD,

Professor, Iran center for dental research, dental school, Shahid Beheshti university of medical sciences, dept. immunology, medical school, Shahid Beheshti university of medical sciences, Iran.

Tel: 09122466490

Fax: (21) 22439970

E-mail: mandana.sattari@sbmu.ac.ir; mandana.sattari@gmail.com

Received: November 12, 2014

Accepted: December 11, 2014

Published: December 12, 2014

Citation: Amini Behbahani A, Sattari M, Mofid R, Ganji A (2014) Interleukin-22 (IL-22) Gingival Gene Expression and GCF Concentration in Periodontal Health and Disease. Int J Dentistry Oral Sci. 1(2), 21-25. doi: http://dx.doi.org/10.19070/2377-8075-140005

Copyright: Sattari $\mathbf{M}^{\odot}$ 2014. This is an open-access article distributed under the terms of the Creative Commons Attribution License, which permits unrestricted use, distribution and reproduction in any medium, provided the original author and source are credited.

\section{Introduction}

Periodontitis is an infectious inflammatory disease of supporting structures of periodontium. Gingivitis and Chronic periodontitis are two major types of periodontal diseases and are of high prevalence among different societies. Although it has been well known that the initiation of periodontal disease depends on periodontopathic bacteria and their products, it is well recognized that the extent and severity of tissue destruction are not necessarily in accordance to bacterial load. In fact, the main determinant of periodontal tissue breakdown is inflammatory response of the body in an attempt to protect the host [1].

For near two decades, $\mathrm{T}_{\mathrm{H}} 1 / \mathrm{T}_{\mathrm{H}} 2$ ( $\mathrm{T}$ helper1/ $\mathrm{T}$ helper2) interaction was the basis of a majority of researches about periodontal disease, however, as many other diseases this model cannot describe thoroughly the progression pattern of periodontal disease. Recently, new $\mathrm{CD}^{+} \mathrm{T}$ cell subsets has been identified that can explain the discrepancies in $\mathrm{T}_{\mathrm{H}} 1 / \mathrm{T}_{\mathrm{H}} 2$ classic model. Such as $\mathrm{T}_{\mathrm{H}} 17$ cells, because IL-17 (Interleukin-17) is the main cytokine, which is produced by these cells. In addition to IL-17, they can also produce IL-22. The other subset is $\mathrm{T}_{\mathrm{H}} 22$ that is characterized by the secretion of IL-22 and TNF-alpha, but not IFN-gamma, IL-4, or IL-17 [2]. In addition to IL-17, one another important cytokine of $\mathrm{T}_{\mathrm{H}} 17$ is IL-22 [3-6]. that enhances the antimicrobial defense of mucosal surfaces. IL-22 modulates the biology of hepatocytes, epidermal and epithelial cells as well as respiratory and gastrointestinal system cells [7].

To the best of our knowledge there is not enough data about the role of IL-22 in periodontal disease. Of course, it was shown that IL- $1 \beta$ in cooperation with IL-22 could increase $T_{H} 17$ cell accumulation in periodontally diseased tissues to enhance CCL20 production [8] and gingival tissues showed modest or no gene expressions of IL-22 [9]. However there are numerous studies that show a direct relationship between the amount of this cytokine and some diseases such as Crohn's disease, rheumatoid arthritis, psoriasis, atopic dermatitis, sepsis, systemic lupus erythematosous 
(SLE) and allergic asthma [10-17]. On the other hand, some studies suggest a regulatory role for this cytokine $[18,19]$.

In the present study we assessed IL-22 gene expression in gingival tissue and the concentration of this cytokine in gingival crevicular fluid (GCF) in health and various degrees of periodontal disease including gingivitis and moderate to advanced chronic periodontitis to identify its possible role in the pathogenesis of periodontal disease.

\section{Methods}

The present study was reviewed and approved by dental research center of Shahid Beheshti University of medical science, Tehran, Iran. A total number of 60 subjects were included in this study. We examined three groups of patients according to the follows:

Healthy group - This group consisted of patients who required crown-lengthening surgery in one part of their mouth, and no sign of BOP was detected in the operation site at first visit and at the operation session using periodontal probe $^{1^{*}}$. At the first visit, all the local irritating factors including calculus, bacterial plaque, caries, and unfavorable temporary crowns with subgingival margins were removed and the patients were instructed to brush their teeth three times a day and to floss once daily and surgery was scheduled for at least one week later.

Gingivitis group - These patients needed crown-lengthening procedure in one part of their mouth and BOP was detected in the first and second visit and the day of operation. The second visit for these patients was schedules the day before surgery and a thorough scaling and polishing of teeth was performed and oral hygiene instruction was given in this session to prepare the site for a clean classic surgery. In order to increase the homogeneity of gingivitis group (group2) only crown lengthening patients were included in group2.

Both of the above groups had no history of periodontitis and no sign of it was present in any part of their mouth in the first visit of healthy and second visit of gingivitis patients. For both groups a complete periodontal charting was performed prior to entering the study. We defined periodontitis at this stage as probing depth $\geq 5 \mathrm{~mm}$ and clinical attachment level $>2 \mathrm{~mm}$.

Periodontitis group - this group included patients with moderate to severe form of chronic periodontitis [20]. For this group, phase I periodontal therapy consisted of supra and subgingival scaling, root planning and polishing and oral hygiene instruction was accomplished at least one month before surgery and periodontal charting and BOP evaluation was performed at the first visit and one week before surgery and at the operation day after GCF sampling to confirm BOP positivity of site.

\section{Inclusion Criteria}

All the patients were Iranian and were older than 18 recruited from periodontics department of dental faculty of Shahid Be- heshti University of medical science. The study protocol was explained to each subject, and written informed consent was obtained prior to enrollment in the study.

\section{Exclusion Criteria}

Presence of any known systemic disease, pregnancy and breast feeding, any history of cigarette smoking, alcohol consuming or drug abuse, any history of medication uptake that could affect periodontal conditions such as calcium channel blockers, anticonvulsive and immunosuppressive agents, any history of allergy, orthodontic therapy, or antibiotic therapy in the preceding 6 months. In addition, sampling was not performed around wisdom teeth, teeth with heavy occlusal interferences, teeth with combined perio-endo problems or pericoronitis and pathologies such as ulcers, cysts, abscesses or tumors.

\section{GCF sampling}

Two interdental gingival sulci in surgical site of each patient were selected for GCF sampling. These sampling sites were as follows: sites with BOP in gingivitis group, sites without BOP in healthy group, and sites with probing pocket depth $\geq 5 \mathrm{~mm}$ and BOP in periodontitis group. Selected areas were irrigated with normal saline, then dried and isolated by cotton roll. Periostrips ${ }^{2 *}$ were placed in the sulci and remained at place for 30 seconds, then removed and strips contaminated with blood, saliva, pus or bacterial plaques were discarded and sampling was repeated. The two strips from each site were placed into one micro tube. All GCF samples were stored at $-40^{\circ} \mathrm{C}$ until laboratory analysis.

\section{GCF processing and Enzyme Immunoassay}

Appropriate enzyme-linked immunosorbent assay (ELISA) $\mathrm{kit}^{3^{*}}$ was purchased for IL-22. GCF samples were eluted with $350 \mu \mathrm{l}$ PBS and centrifuged for 30 minutes in $4^{\circ} \mathrm{C}$ to minimize retention of protein on the periostrips. The assay was carried out according to manufacturer's recommendation. First, standards and $100 \mu$ of each sample were added to wells and shake for 2 hours at the rate of $100 \mathrm{rpm} .100 \mu \mathrm{l}$ of Conjugated antibody was added after washing and shaking for one hour at room temperature. After washing again, $100 \mu \mathrm{l}$ of streptavidin-biotin was added and shake for another one hour; then $100 \mu$ l of substrate was added to develop color change and incubated for 10 minutes in the dark. Finally $100 \mu \mathrm{l}$ of stopper was added and the plate was placed immediately in the ELISA-reader device and the optical densities were read at $450 \mathrm{~nm}$. The results were expressed as $\mathrm{pg} / \mu \mathrm{l}$ as compared to the standards.

\section{Sampling of gingival tissues}

Samples of gingival tissues (connective tissue and epithelium) were obtained mainly from interdental papilla during internal bevel incision surgeries as mentioned earlier. The samples were placed immediately in cryotubes containing RNA later ${ }^{4 *}$ solution and stored until analysis in $-20^{\circ} \mathrm{C}$.

1. Offset Williams Probe, Hu-Friedy, Chicago, IL.

2. Periopaper, ProFlow, Amityville, NY.

3. Bender MedSystem, Vienna, Austria.

4. Qiagen, Pittsburg, PA. 
Gingival tissues were carried to tubes containing TRIzol $^{5 *}$ and then homogenized using a tissue homogenizer ${ }^{6 *}$. Resultant tissueTRIzol mixture was transferred onto chloroform in a microtube and procedure was continued according to manufacturer instruction. Qualification of RNA was performed using 1\% agarose gel electrophoresis and evaluation of 18sRNA and 28sRNA in transilluminator. For quantification of RNA, an ultraviolet spectrophotometer $^{7 *}$ was used with an absorbance wavelength of 230, 260 and $280 \mathrm{~nm}$. The RNA was treated with gDNA wipeout buffer and then reversed-transcript into cDNA using a random hexamer and oligo dT primer and Quanti script reversed transcriptase.

\section{Quantitative Real-Time PCR}

Gene sequence of IL-22 on chromosome 12 and GAPDH as housekeeping gene was obtained from NCBI website and designing of forward and reverse primers was performed using Gene Runner and Primer Express software ${ }^{8 *}$. To determine the ideal concentration of primers, different concentrations $(0.3,0.5,0.6$, 0.8 and $1 \mu \mathrm{M}$ ) were tested and $0.8 \mu \mathrm{M}$ was selected as the best. SYBR Green I real time PCR assay was carried out in final reaction volume of $25 \mu \mathrm{l}$ with $12.5 \mu \mathrm{l}$ of SYBR Green I Master mix ${ }^{9 *}$ containing $0.8 \mu \mathrm{m}$ of forward and reverse primers according to the criteria proposed by real-time PCR system manufacturer ${ }^{10^{*}}$. Thermal cycling was performed using the following cycling condition: preheating at $95^{\circ} \mathrm{C}$ for 10 minutes, followed by shuttle heating at $95^{\circ} \mathrm{C}$ for 15 seconds and $60^{\circ} \mathrm{C}$ for 1 minute in 40 cycles. At the final stage heating was continued for $95^{\circ} \mathrm{C}$ for 15 seconds, $60^{\circ} \mathrm{C}$ for 30 seconds and $95^{\circ} \mathrm{C}$ for 15 seconds. Calculations to determine the relative level of gene expression were made by reference to the GAPDH in each sample, using cycle threshold method. The data were analyzed by the system software ${ }^{11 *}$. Ct value of reference gene $(\mathrm{GAPDH})$ was subtracted from $\mathrm{Ct}$ value of the target gene (IL-22) to obtain $\Delta \mathrm{Ct}$. After that $\Delta \Delta \mathrm{Ct}$ was calculated ( $\Delta \mathrm{Ct}$ target $-\Delta \mathrm{Ct}$ reference). The calculated $\Delta \Delta \mathrm{Ct}$ was converted to ratio using the ratio formula $\left(\right.$ ratio $\left.=2^{-\Delta \Delta C t}\right)$.

\section{Statistical Analysis}

The data were analyzed by Kolmogorov-Smirnov test to evaluate the normality of the distribution. Study groups were compared using Kruskal-Wallis test and two by two statistical analysis was performed among groups by Mann-Whitney U test. The Spearman test was applied to analyze the correlation between IL-22 concentration and age, Clinical attachment level and probing depth. Finally we analyzed IL-22 concentration in different groups of periodontitis with respect to extent and severity using Kruskal-Wallis test. A P value of $\leq 0.05$ was considered statistically significant. All statistical analyses were done by SPSS 16.0. Because of using non-parametric tests for statistical analysis the ranks of the data is more reliable than mean.

\section{Results}

A summary of the subjects included in study is presented in $\mathrm{Ta}$ ble 1 . There were 8 females and 12 males with a mean age of $40.75 \pm 14.31$ years in healthy group, 7 females and 13 males with a mean age of $42.10 \pm 11.88$ years in gingivitis group and 10 females and 10 males with a mean age of $45.54 \pm 11.06$ years in periodontitis group.

No expression of IL-22 was detected in any of tissue samples using real-time PCR. The results of ELISA test are presented in table 2. Since the distribution of data was not normal, nonparametric statistics were used to avoid the effect that outliers might exert. There were statistically significant differences in IL22 concentration among three groups $(\mathrm{P}<0.001)$; the concentration of IL-22 was significantly higher in periodontitis group than gingivitis group $(\mathrm{P}<0.05)$ and in gingivitis group in comparison to healthy group $(\mathrm{P}<0.05)$. The difference among various groups of periodontitis including generalized severe, generalized moderate, localized severe and localized moderate was not statistically significant. There was not any correlation between age and IL-22 in any of study groups. A positive correlation was observed between Il-22 concentration and clinical parameters entirely but no correlation was detected in each group.

Table 1. Descriptive characteristics of the sites of three subject groups

\begin{tabular}{|c|c|c|c|c|c|}
\hline \multirow[t]{2}{*}{ group } & \multirow{2}{*}{$\begin{array}{c}\mathrm{PD}(\mathrm{mm}) \\
\text { Mean } \pm \mathrm{SD}\end{array}$} & \multirow{2}{*}{$\begin{array}{l}\text { CAL }(\mathrm{mm}) \\
\text { Mean } \pm \text { SD }\end{array}$} & \multirow{2}{*}{$\begin{array}{l}\text { Age(years) } \\
\text { Mean } \pm \text { SD }\end{array}$} & \multicolumn{2}{|c|}{ Subjects(n) } \\
\hline & & & & Male & Female \\
\hline Healthy & $2.45 \pm 0.76$ & $0.55 \pm 0.51$ & $40.75 \pm 14.31$ & 12 & 8 \\
\hline Gingivitis & $2.90 \pm 0.55$ & $1.00 \pm 0.56$ & $42.10 \pm 11.88$ & 13 & 7 \\
\hline Periodontitis & $7.95 \pm 1.43$ & $6.17 \pm 1.68$ & $45.54 \pm 11.06$ & 10 & 10 \\
\hline
\end{tabular}

Table 2. GCF levels of IL-22 in different study groups and kruskal-Wallis ranking

\begin{tabular}{|c|c|c|c|c|}
\hline group & Maximum $(\mathrm{pg} / \mathrm{ml})$ & Minimum $(\mathrm{pg} / \mathrm{ml})$ & Mean $\pm \mathrm{SD}(\mathrm{pg} / \mathrm{ml})$ & Kruskal-Wallis Rank \\
\hline Healthy & 9330.00 & 0.00 & $6681.70 \pm 1766.44$ & 18.32 \\
\hline Gingivitis & 25448.00 & 6246.00 & $8661.40 \pm 4268.65$ & $31.15^{*}$ \\
\hline Periodontitis & 12862.00 & 6653.00 & $8562.65 \pm 1324.65$ & $42.02 *$ \\
\hline
\end{tabular}

5. Qiagen, Pittsburg, PA.

6. Qiagen TissueLyser-MM301, Pittsburgh, PA.

7. NanoDrop 3300, Wilmington, DE.

8. Applied Biosystem, Foster City, CA, USA.

9. Applied Biosystems, Warrington,UK.

10. ABI 7300 Real-time PCR system, Applied biosystems, California.

11. ABI PRISM SDS 2.0, Applied biosystems, California. 


\section{Discussion}

This study had two interesting findings. One is an increase in GCF concentration of IL-22 from health to gingivitis and from gingivitis to periodontitis. The second is that the concentration of this cytokine did not depend on extent and severity of periodontitis and there was not any correlation between clinical measures and IL-22 concentration in chronic periodontitis.

It has been suggested that IL-22 has a role in primary defense of host against attachment of pathogenic bacteria [5,21,22], so its increase in inflammatory diseases such as periodontitis is somewhat predictable. It seems that sustained stimulation from bacteria in transition from gingivitis to periodontitis leads to increase in production rate of IL-22 as a defensive mechanism. Since there is no similar studies in periodontal disease a direct comparison of the results is not possible. Hosokawa et al in 2009 indicated a stimulatory effect of IL-22 on CXCL10 chemokine production of gingival fibroblasts that were subjected to IFN- $\gamma$; on the other hand, IL-22 and IL-17 had inhibitory effect on production of this chemokine if fibroblasts were treated by TNF- $\alpha$ before [23].

The increase in the amount of IL-22 in GCF, from clinically healthy gingiva to gingivitis and from gingivitis to chronic periodontitis might have a predictive value in estimating the susceptibility of patients to periodontitis. It is of paramount importance when planning comprehensive therapies for patients.

One interesting point in our study is that no significant correlation was found between extent and severity of periodontitis and IL-22 concentration that might propose that this cytokine has not an important role in progression of disease and other mechanisms should be considered in this regard. In addition, Aranha et al (2013) considered a protective role for $\mathrm{T}_{\mathrm{H}} 9$ and $\mathrm{T}_{\mathrm{H}} 22$ cytokines [24]; and Katogoe et al (2012) suggested that IL-22 has the potential to promote mineralizing activity in PDL cells and to develop appropriate regenerative therapy [9].

We could not detect IL-22 mRNA in any of tissue samples despite high concentration of the protein in GCF. Of course, katoKogoe et al found that gingival tissues showed modest or no gene expressions of IL-22 [9]. It may be indicative of another source of this cytokine in periodontium that is not included in our samples such as PDL and or alveolar bone. Ikeuchi and colleagues found that in rheumatoid arthritis which shares some similarities with chronic periodontitis this cytokine is produced by synovial fibroblasts and macrophages [17]. Another possibility is that IL22 brings to periodontal tissues via blood stream. There are some reports of increased blood level of this cytokine in some autoimmune diseases such as Crohn's disease; however there was not a concurrent increase in the amount of other related cytokines such as IL-17 [16,21]. Wolk and colleagues reported that systemic IL22 can induce LPS binding protein from hepatocytes to suppress LPS effects [7]. Since the majority of periodontal pathogens are gram negative in nature, it can be assumed that overproduction of IL-22 is a defense mechanism against systemic effects of LPS.

Many studies have demonstrated that IL-22 had no receptor on immune cells and its membrane-bound receptor is present on non-leukocyte cells such as pancreatic acinar cells, keratinocytes, and hepatocytes [6]. It has been shown that, this cytokine induces the production of acute phase proteins, mucins and antimicrobial peptides to maintain tissue integrity during inflammation $[5,14]$.
Due to its unique selective regulatory effects on tissue response, IL-22 can be considered as a potential therapeutic target for chronic inflammatory diseases such as periodontitis. In contrast to current immunosuppressive therapies such as TNF- $\alpha$ inhibitors which can induce unwanted suppression in immune response against infections, IL-22 can specifically regulate tissue response without direct effect on immune system.

In conclusion, in this study we found an increase in GCF concentration of IL-22 from health to gingivitis and from gingivitis to chronic periodontitis; so this cytokine can be considered as an indicator of susceptibility to periodontitis for scheduling comprehensive treatments. There was not any correlation between the amount of this cytokine in GCF and extent and severity of periodontitis, so other mediators may be more important in this progression. Since IL-22 has no effect on primary immune cells, it can be considered as a therapeutic target of chronic inflammatory diseases without substantial effect on immune system.

\section{Acknowledgements}

This study was granted by Iran Center for Dental Research, Dental School, Shahid Beheshti University of Medical Sciences. The authors report no conflicts of interest related to present study.

\section{References}

[1]. Tabeta K, Shimada Y, Tai H, Ishihara Y, Noguchi T, et al (2009) Assessment of chromosome 19 for genetic association in severe chronic periodontitis. J Periodontol 80(4):663-71

[2]. Gaffen S.L, Hajishengallis G (2008) A new inflammatory cytokine on the block: Re-thinking periodontal disease and the TH1/TH2 paradigm in the context of TH17 cells and IL-17. J Dent Res 87(9): 817-828.

[3]. Eyerich S, Eyerich K, Pennino D, Carbone T, Nasorri F, et al (2009) TH22 cells represent a distinct human $\mathrm{T}$ cell subset involved in epidermal immunity and remodeling. J Clin Invest. 119(12):3573-85.

[4]. Zheng Y, Danilenko DM, Valdez P, Ian Kasman, Jeffrey Eastham-Anderson ,et al (2007) Interleukin-22, a TH17 cytokine, mediates IL-23-induced dermal inflammation and acanthosis. Nature 445:648-651.

[5]. Liang SC, Tan XY, Luxenberg DP, Karim R, Dunussi-Joannopoulos K, et al (2006) Interleukin (IL)-22 and IL-17 are coexpressed by TH17 cells and cooperatively enhance expression of antibacterial peptides. J Exp Med 203:2271-2279.

[6]. Wolk K, Kunz S, Witte E, Friedrich M, Asadullah K, et al (2004) IL-22 increases the innate immunity of tissues. Immunity 21:241-254.

[7]. Wolk K, Witte E, Hoffmann U, Doecke WD, Endesfelder S, et al (2007) IL-22 induces lipopolysaccharide-binding protein in hepatocytes: a potential systemic role of IL-22 in Crohn's disease. J Immunology 178:5973-5981.

[8]. Hosokawa Y, Hosokawa I, Shindo S, Ozaki K, Matsuo T (2014) IL-22 Enhances CCL20 Production in IL-1 $\beta$-Stimulated Human Gingival Fibroblasts. Inflammation 37(6):2062-6.

[9]. Kato-Kogoe N, Nishioka T, Kawabe M, Kataoka F, Yamanegi K, et al (2012) The promotional effect of IL-22 on mineralization activity of periodontal ligament cells. Cytokine.59(1):41-8.

[10]. Pène J, Chevalier S, Preisser L, Vénéreau E, Guilleux MH et al (2008) Chronically inflamed human tissues are infiltrated by highly differentiated TH17 lymphocytes. J Immunol 180:7423-7430.

[11]. Ma HL, Liang S, Li J, Lee Napierata, Tom Brown,et al (2008) IL-22 is required for TH17 cell-mediated pathology in a mouse model of psoriasis-like skin inflammation. J Clin Invest 118:597-607.

[12]. Hegen M,et al (2007) IL-22, a TH17 and TH1 cytokine, regulates local tissue inflammation in the context of autoimmune disease. Cytokine 2007; 39(1): 15-15

[13]. Bingold TM, Ziesché E, Scheller, Sadik CD, Franck K, et al (2008) Interleukin-22 in sepsis. Cytokine 43(3): 247-248.

[14]. Liang SC, et al (2009) IL-22, a TH17 cytokine, induces a systemic acute phase response. Cytokine 48(1-2): 36-37.

[15]. Nograles KE, Zaba LC, Shemer A, Judilyn Fuentes-Duculan, Irma Cardinale, et al (2009) IL-22-producing "TH22" T cells account for upregulated IL-22 in atopic dermatitis despite reduced IL-17 producing Th17 T cells. J Allergy Clin Immunol 123:1244-52.

[16]. Pan HF, Zhao XF, Yuan H, Zhang WH, Li XP, et al (2009) Decreased serum 
IL-22 levels in patients with systemic lupus erythematosus. Clin Chim Acta 401(1-2): 179-180.

[17]. Ikuechi H, Kuroiwa T, Hiramatsu N, Kaneko Y, Hiromura K, et al (2005) Expression of interleukin-22 in rheumatoid arthritis: potential role as a proinflammatory cytokine. Arthritis Rheum 52(4):1037-46.

[18]. Nagalakshmi ML, Rascle A, Zurawski S, Menon S, Malefyt R (2004) Interleukin-22 activates STAT3 and induces IL-10 by colon epithelial cells. Int Immunophar 4:679-691.

[19]. Wolk K, Sabat R (2006) Interleukin-22: a novel T- and NK-cell derived cytokine that regulates the biology of tissue cells. Cytokine Growth Factor Rev 17:367-380.

[20]. Newmann MG, Takei HH, Klokkevold PR, Carranza FA (2006) Carranza's clinical periodontology, W.B. Saunders 10; 496-497.

[21]. Zenewicz LA, Yancopoulos GD, Valenzuela DM, Andrew J. Murphy, Margaret Karow et al (2007) Interleukin-22 but not interleukin-17 provides protection to hepatocytes during acute liver inflammation. Immunity 27:647-
659.

[22]. Zheng Y, Valdez P.A, Danilenko D.M, Hu Y, Sa SM, et al (2008) Interleukin-22 mediates early host defense against attaching and effacing bacterial pathogens. Nature Med 14: 282-289.

[23]. Hosokawa Y, Hosokawa I, Ozaki K, Nakae H, Matsuo T (2009) Cytokines differentially regulate CXCL10 production by interferon-gamma-stimulated or tumor necrosis factor-alpha-stimulated human gingival fibroblasts. J Periodontal Res 44(2):225-31.

[24]. Aranha AM, Repeke CE, Garlet TP, Vieira AE, Campanelli AP (2013) Evidence supporting a protective role for th9 and th22 cytokines in human and experimental periapical lesions. J Endod. 39(1):83-7. 